\title{
FORMATION OF THE CULTURE OF INTERNATIONAL COMMUNICATION OF PHD DOCTORS OF THE SPECIALTY "PHYSICAL CULTURE AND SPORTS"
}

\author{
R. Dyussupova, L. Kudashova, Zh. Dyussupova \\ Kazakh Academy of Sport and Tourism
}

\begin{abstract}
Annotation. The article gives an analysis of the expediency of the inclusion of the discipline "Pedagogical foundations of the culture of international communication" in the compulsory component of the educational program of the doctorate of the specialty "Physical Culture and Sport". The actual competences acquired by doctoral students have been developed, examined and scientifically substantiated. The issues are discussed on the subject and content of the training curriculum, which are necessary for the preparation of doctoral students in this case, which enable them to manage problems and make decisions that arise in the formation of a culture of international communication. The introduction of this discipline makes it possible to expand the abilities and skills of using pedagogical bases of the culture of international communication in the process of professional activity by doctoral students.

The purpose. To scientifically justify the necessity of introducing the specialty 6D010800 - "Physical Culture and Sport" discipline "Pedagogical bases of the culture of international communication" into the compulsory component cycle of the educational program for PhD students to improve the competencies of doctoral students in solving problems of international communication in the specialty "Physical Culture and Sport" in Kazakhstan.

Methodology. Analysis and systematization of scientific and methodological literature, state standards of postgraduate education, development of the content of the curriculum, approbation of the developed program and content of the discipline, generalization of pedagogical experience.

Results. The design of the educational technology of discipline was based on the principles of the problem modular content of the educational process; transition from educational activity to an independent scientific-cognitive and research. The study of the course "Pedagogical foundations of the culture of international communication" contributes to the formation of the following key competencies for the doctoral candidate: to have knowledge and practical skills in the discipline "Pedagogical bases of the culture of international communication"; be able to set and solve problems, to make non-standard decisions; to study, to plan, to model, to regulate and organize the activity of students; to apply multimedia and Internet technologies in teaching and coaching activities in the culture of international communication. Subject competencies presuppose knowledge of the basic principles and laws of the theory of the culture of international communication; knowledge of the national diversity of cultures in the modern world; the ability in practice to apply the knowledge gained about the culture of international communication. Special competencies include the knowledge, skills and skills of applying theoretical knowledge in professional activities; the ability to find non-standard and alternative solutions in the event of problems on the issues of the culture of international communication; willingness to apply pedagogical methods and technologies for scientifically based formation of a culture of international communication.
\end{abstract}

Key words: culture of international communication, culture of international communication in the field of physical culture and sport, doctorate of the specialty "Physical culture and sport", competences of doctoral students.

Introduction. At the present stage of the development of education in Kazakhstan, a special role is assigned to the training of highly qualified specialists, which is ensured by training on the basis of awarding a state and targeted grant to doctoral studies at higher educational institutions of the Republic of Kazakhstan in the specialty "Physical Culture and Sports".
There are several directions in the literature in interpreting the essence of the culture of international communication. Firstly, the culture of international communication was reflected at the level of ethical problems, where it is viewed through the correlation of categories and laws of this discipline. Secondly, the culture of international communication is viewed from the point of view of the specifics of the values that make up its composition. In 
this direction, the main attention is drawn to such issues as the development of subjects of international communication. And, thirdly, the culture of international communication is studied as an integral part of political culture.

Special attention should be paid to the point of view on the problems of international nature and the formation of a culture of international communication among such scientists as Dzhunusov MS, Likhachev DS, Abdulatipov RG and others, who devoted most of their scientific work to these problems.

Dzhunusov M.S. [1] argued that national cultures, distinct in nature, constitute a world civilization, while all nations are equal carriers of universal human values. World culture cannot be full if it lacks the "sound" of the culture of representatives of all nations and nationalities, and at the same time, the mutual influence, interaction and mutual enrichment of unique national cultures form the essence of world culture.

Abdulatipov RG [2] considering the problems in the field of national and international relations, believes that every person, regardless of belonging to one or another nationality, has the right to freely study his language, develop a national culture, obtain full information about it, and assert its identity. The concept of national relations, according to the author, is based on two principles: parity of all nationalities and partnership, cooperation.

The need to study his own national culture was considered in his works by D. Likhachev. [3], who said that only the knowledge of one's own culture makes it possible to respect a different culture, to accept and recognize the existence of different cultures.

In the literature there is the use of this category in a wide and narrow significance. In a wide significance the culture of international communication means: first, the development of people's understanding, assessment of national and international processes from the dialectical positions; secondly, scientific management, regulation of national and international relations; thirdly, the formation of an internationalist consciousness in each individual, a feeling of friendship among peoples. In a narrow sense, the culture of international communication is considered in more detail and is defined as the ability of the individual to behave in interpersonal contact with people of different nationalities, showing respect for language, life, and traditions.

In recent years, there has been a tendency to study the culture of international communication through the prism of solving the didactic tasks of various disciplines, as well as in the educational process both in the general education school and in higher education institutions, and an attempt to explore the content side of this phenomenon

In general, the scientific literature covers the theoretical prerequisites for studying this phenomenon, and methodological approaches to the solution of the phenomenon are determined.

The introduction of the discipline "Pedagogical foundations of the culture of international communication" is aimed at raising the level of theoretical and practical mastering of doctoral students with knowledge, skills and abilities in the field of formation of intercultural and international interaction; analysis of the system of knowledge about trends and directions of socio-cultural development; mastering knowledge about the cultural and ethnic specifics of the peoples living in the republic; mastering the methods of managing the culture of international communication in classrooms.

The objectives of the discipline course are mastering the doctoral students in the basics of the theory of the culture of international communication; system of knowledge about trends and directions of personality development within the framework of knowledge of culture, history of native people and peoples of the Republic of Kazakhstan; pedagogy of international communication.

Formation of competencies of doctoral students occurs in the study of pedagogical technologies on international interaction and intercultural communication in social and professional activities; analysis of patterns of development of national culture; interpersonal relationships between people of different nationalities; assessment of cultural, confessional and ethnic specifics on the example of the native culture and cultures of the peoples of Kazakhstan, which is reflected in the following modules:

module 1. Theoretical and methodological ap- 
proaches to the study of the culture of international communication, which address issues of the history of the problem, the formation of a culture of international communication and international harmony in the sport, modern approaches to the content of the culture of international communication, methods of pedagogical research;

module 2. The culture of international communication as a pedagogical problem includes the study of such topics as priority areas of modern education in the formation of a culture of international communication, pedagogical technologies for the formation of the culture of international communication, physical culture and the sport as a factor in the formation of a culture of international communication, the role of the physical education teacher in shaping the school culture, the basis of cultural communication and primary value orientations in school and higher education, the interaction of teachers and parents in education of the culture of international communication.

Particular attention is paid to the study by doctoral students of the methods of scientific research, which reflect the real situation on the problem of the culture of international communication, which contributes to the formation of research competence.

In the process of studying the discipline, doctoral students consolidate knowledge of the diversity of cultures in the modern world; expand the range of theoretical knowledge in the sphere of international communication; acquire practical skills in the use of active means, in the process of interpersonal communication, in socio-cultural situations and their solutions; form practical skills and ability to regulate the situation in society in accordance with the national, multinational and multicultural problem in the region and the country.

Discipline reflects the integration of special knowledge and skills, adequate actions and actions, manifested in interpersonal contacts and interactions of representatives of different nationalities, allowing them quickly and without any problems to achieve mutual understanding and harmony in the common interest.

Pedagogy of international communication as an obligatory university academic discipline entered the Russian State Educational Standard of Higher Professional Education [4], on the basis of which a curriculum and teaching aids were developed. The pedagogy of international communication has become an institutional component of the state pedagogical policy. For example, in Rostov-on-Don city the course "Culture of international communication" was introduced, in the program of Tomsk State University - the course "Pedagogy of international communication in the context of pedagogical sciences", it is proposed to build a technology for implementing the culture of international communication by introducing the discipline "Psychology and pedagogy of international communication ". The introduction of these courses in the education system of the Russian Federation testifies to the availability of the developed scientific and methodological support of the culture of international communication problem.

To clarify the level of international relations, a questionnaire was conducted for students of the specialty "Physical Culture and Sport", which showed that insufficient attention is paid to the process of formation of a culture of international communication in higher education, as evidenced by the answers of respondents who feel negative attitude of others due to nationality up to $12.4 \%$ ).

The results of the questionnaire with the 1st year students (18-23) of the specialty "Physical Culture and Sport" revealed the following problems: $75.6 \%$ of students show friendly and trusting attitudes toward representatives of other nationalities, 19.2\% noted that they characterize relations as "Neutral", $5.2 \%$ believe that they had a hostile attitude towards themselves and others because of their nationality. At the same time, with participation in sports competitions with a representative of a different nationality, $69.8 \%$ of athletes are well-wishers, $8.2 \%$ of respondents said that nationality does not matter, $22.0 \%$ consider it the main achievement of victory. At the same time, $83.4 \%$ of students believe that sports contribute to the development of friendliness and respect for representatives of another nationality; $100 \%$ of respondents confirmed the need to know their native language; At the same time, $8.5 \%$ do not consider it necessary to study the state language, because they do not plan to live in Kazakhstan; $78 \%$ of students recognize the need to learn English as an international language, but do not plan to study it in the near future; $13.5 \%$ do not 
consider it necessary to study nonnative language, linking their future with work in a mono-national environment.

Identified doubts of respondents confirm the necessity of conducting educational work in higher educational institutions to cultivate a respectful attitude of ethnocultural tolerance and understanding the value of each language and each culture.

Taking into account the obtained results will allow expanding the skills and skills of using doctoral the pedagogical bases of management of problems of international communication in the university and in the field of physical culture and sports.

\section{Conclusion.}

The questionnaire survey showed the relevance of the culture of international communication problem and the lack of formation in a significant part of the students of the correct social orientation towards this issue, which indicates the need to raise the educational level of curators and advisors to such a sensitive sphere of human relations, with cultivating respect for ethno-cultures and understanding the value of each individual, each language and of each culture, which can be realized as a special training in the culture of international communication through this discipline, as for undergraduates, and doctoral students in the sphere of "Physical Culture and Sport".

Given the urgency of the problem at the present stage of development of Kazakhstan society, we consider it necessary to introduce this course "Pedagogical foundations of the culture of international communication" in the cycle of compulsory $\mathrm{PhD}$ studies of all specialties.

\section{Literature}

Dzhunusov M.S. On the measure of the identity of national cultures / / Sociological research - 2002 - № 5 - p. 125-127.

Abdulatipov R. It is not necessary to establish ethnic dictatorship // http://svpressa.ru

Likhachev D. S. Memory overcomes time // Our heritage - 1988.- Volume I - p.1-4.

Russian State Educational Standard of Higher Professional Education. Federal Law "On Higher and Post-Graduate Professional Education" // http://www. electorat.info/encyclopedia. 